\title{
Bullet in the Para Pharyngeal Space
}

\author{
Alaa ben Ramadan ${ }^{1}$, Salem Farhat ${ }^{2}$ and Omar Mohamed Alwahedi $i^{3^{*}}$ \\ ${ }^{1}$ Alaa ben Ramadan, FRCS, Consultant Neurosurgeon, Africa \\ ${ }^{2}$ Salem Farhat, FRCS, MSc, DLO consultant Otolaryngologist, Africa \\ ${ }^{3}$ Omar Alwahedi, Neurosurgical Registrar, Africa
}

Submission: May 07, 2017; Published: May 30, 2017

*Corresponding author: Omar Mohamed Alwahedi, Tripoli central hospital, Neurosurgical Department and Trauma Department, Libya, Africa, Tel: 00218926039260; Email: omarwahedi@gmail.com

\begin{abstract}
Bullet injuries to head and neck are usually associated with high mortality and morbidity due to a number of vital structures lying in close proximity; bullets in the Para pharyngeal space are rare. We present a case of 27 years old male with history of gunshot to the head with inlet in the posterior auricular region and a bullet lodged in the lateral Para pharyngeal space.

Keywords: Bullets; Metallic foreign body; Gunshot head and neck; Para pharyngeal space; Surgical removal
\end{abstract}

\section{Introduction}

Gunshot injuries incidence increasing in Libya in the last few years, Gunshot wounds to the head (GSWH) account for the majority of penetrating brain injuries, and comprise $\approx 35 \%$ of deaths from brain injury in persons $<45$ years old. GSWH are the most lethal type of head injury, $\approx$ two-thirds die at the scene, and GSWH ultimately are the proximal cause of death in $>90 \%$ of victims. Penetrating wounds to the maxillofacial region pose a significant challenge for surgeons as they often comprise serious soft and bone defects. They may cause significant damage to the closely arranged structures in this region, and the bullet's trajectory can be very difficult to determine. A very unique case of penetrating bullet injury came walking to our clinic with as minimal damage to the head and neck as one could possibly imagine.

\section{General Principles}

On admission victims of gunshot injuries are best managed by standard advanced trauma life support (ATLS) protocols. Even seemingly innocuous wounds deserve attention, given the erratic nature of the wounds. Specific attention must be given to the possibility of multiple injuries; it is imperative to thoroughly inspect the patient for multiple entrance and exit wounds. Visually disturbing but not life-threatening facial gunshot injuries can distract medical personnel from other more subtle lethal injuries such as a penetrating thoracic wound that entered through the back. Ophthalmologic and neurosurgical consultations are obtained when indicated. Approximately $17 \%$ of patients with a GSW to the face have associated brain injuries, and $8 \%$ have associated cervical spine injuries. Eye injuries are present in approximately $13 \%$ certain considerations for gunshot injuries should be emphasized.

\section{Case Report}

A 27 years old Libyan male presented to our neurosurgical clinic at Tripoli central hospital, with a history of gunshot to the head two days back. He was fully conscious, oriented and breathing spontaneously his GCS (Glasgow coma scale) of 15/15 E4V5M6. He was in a good stable general condition. He had no history of chronic illness. He complained of left sided hearing loss. On examination, he had an inlet wound behind his left ear and no exit wound, His left ear was full of blood and had left lower motor neuron facial paralysis. Hearing assessment revealed left mixed hearing loss. The wound was infected and has been treated by debridement and secondary suturing. Bacteriological swab result showed growth of Staph .aureus, the patient was admitted to our neurosurgical ward and had intravenous combination of ceftriaxone and metronidazole.

Computed topography to the head and neck with 3D reconstruction and CT angiography were carried out. The scans showed evidence of hyperdense metallic foreign body in the left parapharyngeal space, anterior to the arch of the fist cervical vertebra and medial to the medial pterygoid muscle. Fracture of pterygo-palatine fossa bone, mastoid bone and pterygoid plate were noted as well as opacifaction of the middle ear and contusion of pterygopalatine fossa soft tissue.The angiography was normal. His laboratory investigations were within normal limits. The bullet was removed successfully without any surgical complications. The procedure was carried out by a joint team 
of neurosurgery and otolaryngology, using a trans-oral approach and splitting the soft palate. The wound was closed using an absorbable suture and treated with dexamethasone to reduce the soft tissue oedema. He made uneventual recovery and discharged after few days.

\section{Result}

Unique case of a foreign body (bullet) lodged in the Para pharyngeal space, which was surgically removed without complications (Figure 1).

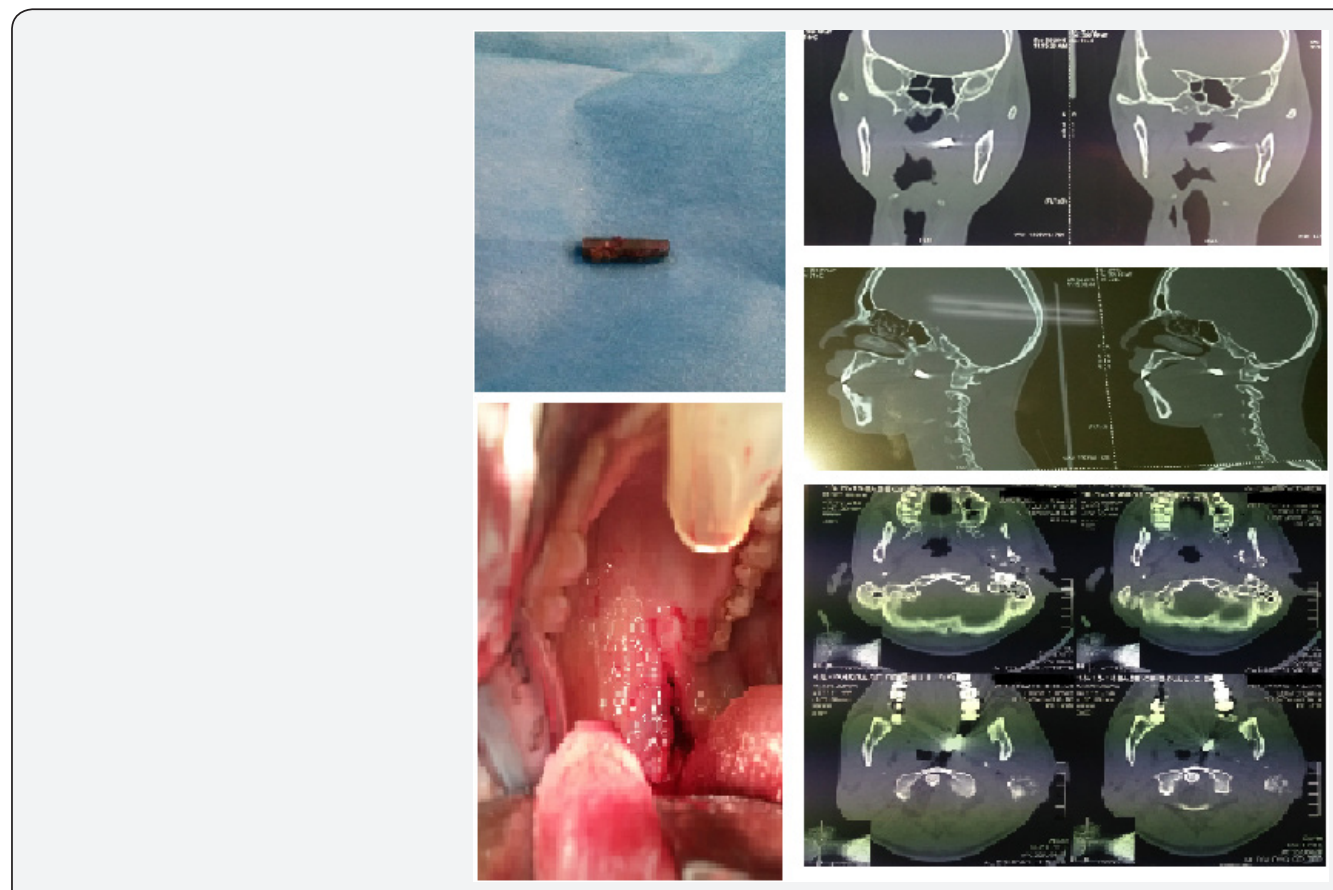

Figure 1: Unique case of a foreign body (bullet) lodged in the Para pharyngeal space, which was surgically removed without complications.

\section{Discussion}

\section{Facial Nerve}

Damage to the facial nerve is present in only 3 to $6 \%$ of civilian GSWs to the face. This is most likely because low energy weapons are involved in most of these cases. However, such damage is not uncommon in injuries inflicted by higher velocity firearms. Careful documentation at the earliest possible opportunity is important. If a functioning nerve becomes nonfunctional secondary to swelling, the surgeon can be reasonably confident that function will return. Obvious transection of the nerve requires repair. In heavily contaminated wounds, repair should be delayed for 48 to 72 hours, given the possibility that grafts will be required to span damaged segments. Beyond 72 hours distal branches of the facial nerve will not respond to a nerve stimulator, making their identification difficult. If possible, tagging the branches with suture at the initial surgery is invaluable. Extensive damage to the proximal nerve may require a temporal bone dissection to identify a viable proximal nerve for grafting. Injuries distal to a line dropped vertically from the lateral canthus (zone of arborization) do not typically require repair because of the multiple interconnections distal to this line and the reasonable expectation of return of function, even if the nerve is temporarily nonfunctioning.

\section{Contamination}

It should be remembered that projectiles from firearms are not sterile, the heat generated by the discharge of the propellant as well as the friction between the bullet and barrel is not sufficient to sterilize the bullet. Contamination can occur from the bullet and also from skin flora and foreign bodies (clothing) carried into the wound. Historically, streptococcal bacteremia was the most important cause of death on the battlefield in the preantibiotic era. Wounds in which the bullet traverses the aerodigestive tract or paranasal sinuses are at particular risk. Devitalized tissue and vascular congestion leads to an ideal environment for bacterial growth. Prophylactic coverage with broad-spectrum antibiotics, typically a second-generation cephalosporin, and tetanus prophylaxis, when indicated, should be initiated in all gunshot wounds [1,2]. Extensive surgical débridement is rarely indicated in wounds consistent with low velocity projectiles to prevent infection.

Removal of projectiles, a well-worn tradition in Hollywood, is less commonly indicated in reality. The need for the removal of bullets must be balanced against the real risk of increasing damage. Lead toxicity is a rare complication tha tdoes not typically justify the routine removal of bullet fragments. Removal o f intra-articular bullet fragments should be considered when 
the increased risk of lead toxicity is associated with fragments within joint spaces and the potential for long term deterioration of the joint. Finally, consideration may be given to the removal of brass- or copper-jacketed bullets that are in close proximity to central or major peripheral nerves because of potential neurotoxicity. It is important to remember that bullet fragments are potential evidence and an appropriate chain of custody is required.

Most hospitals have a protocol in place to ensure that this chain is unbroken from the time they are retrieved to when they are logged in as evidence. This usually involves a police officer or other designee taking direct possession of the bullet or fragments in the operating room or nearby. Documentation of injuries with photographs can aid in reconstructing the events leading to the injury and recording where fragments were retrieved. Since some assaults have injury patterns similar to suicides, it is important to consider this chain of custody because subsequent investigations may reveal that an apparent suicide was actually an assault

\section{Conclusion}

The development of firearms heralded a new era in surgery as well as warfare. Evolution of more efficient weapons continues to force surgeons to improve techniques. Similarly, improvement in the management of GSWs to the face has paralleled the advancement of oral and maxillofacial surgery, Techniques and skills developed by oral and maxillofacial surgeons in the management of these injuries translated directly to other areas such as bone grafting, and promoted the growth and expanding scope of the specialty. Improvements in imaging and fixation techniques have resulted in an evolution in management, with an emphasis on earlier repair, preventing complications and a focus on improvement in quality of life.

\section{Acknowledgement}

We thank the team of radiologists in the Department of Radiology, for their input in discussion of the patient's management.

\section{References}

1. Greenberg hand book of neurosurgery

2. Gunshot Injuries Jon D. Holmes, DMD, MD in: Peterson's principles of Oral and maxillofacial Surgery Second Edition, BC Decker Inc.

\section{Your next submission with Juniper Publishers will reach you the below assets}

- Quality Editorial service

- Swift Peer Review

- Reprints availability

- E-prints Service

- Manuscript Podcast for convenient understanding

- Global attainment for your research

- Manuscript accessibility in different formats ( Pdf, E-pub, Full Text, Audio)

- Unceasing customer service

Track the below URL for one-step submission https://juniperpublishers.com/online-submission.php 